\title{
Antiangiogenic Activity and Pharmacogenomics of Medicinal Plants from Traditional Korean Medicine
}

\author{
Ean-Jeong Seo, ${ }^{1}$ Victor Kuete, ${ }^{1,2}$ Onat Kadioglu, ${ }^{1}$ Benjamin Krusche, ${ }^{1}$ Sven Schröder, ${ }^{3}$ \\ Henry Johannes Greten, ${ }^{4,5}$ Joachim Arend, ${ }^{1}$ Ik-Soo Lee, ${ }^{6}$ and Thomas Efferth ${ }^{1}$ \\ ${ }^{1}$ Department of Pharmaceutical Biology, Institute of Pharmacy and Biochemistry, Johannes Gutenberg University, \\ Staudinger Weg 5, 55128 Mainz, Germany \\ ${ }^{2}$ Department of Biochemistry, Faculty of Science, University of Dschang, Cameroon \\ ${ }^{3}$ HanseMerkur Center for Traditional Chinese Medicine, University Hospital Eppendorf, Hamburg, Germany \\ ${ }^{4}$ Biomedical Sciences Institute Abel Salazar, University of Porto, Portugal \\ ${ }^{5}$ Heidelberg School of Chinese Medicine, Heidelberg, Germany \\ ${ }^{6}$ College of Pharmacy, Chonnam National University, Gwangju, Republic of Korea
}

Correspondence should be addressed to Thomas Efferth; efferth@uni-mainz.de

Received 28 March 2013; Revised 9 May 2013; Accepted 14 May 2013

Academic Editor: Sookyung Lee

Copyright (C) 2013 Ean-Jeong Seo et al. This is an open access article distributed under the Creative Commons Attribution License, which permits unrestricted use, distribution, and reproduction in any medium, provided the original work is properly cited.

Aim. In the present study, we investigated the antiangiogenic properties of 59 plants used in traditional Korean medicine. Selected phytochemicals were investigated in more detail for their modes of action. Methods. A modified chicken-chorioallantoicmembrane (CAM) assay using quail eggs was applied to test for antiangiogenic effects of plant extracts. A molecular docking in silico approached the binding of plant constituents to the vascular endothelial growth factor receptors 1 and 2 (VEGFR1, VEGFR2). Microarray-based mRNA expression profiling was employed to correlate the $50 \%$ inhibition concentrations ( IC $_{50}$ ) of a panel of 60 NCI cell lines to these phytochemicals. Results. Extracts from Acer mono leaves, Reynoutria sachalniensis fruits, Cinnamomum japonicum stems, Eurya japonica leaves, Adenophora racemosa whole plant, Caryopteris incana leaves-stems, and Schisandra chinensis stems inhibited angiogenesis more than 50\% in quail eggs. Selected phytochemicals from Korean plants were analyzed in more detail using microarray-based mRNA expression profiles and molecular docking to VEGFR1 and VEGFR2. These results indicate multifactorial modes of action of these natural products. Conclusion. The antiangiogenic activity of plants used in traditional Korean medicine implicates their possible application for diseases where inhibition of blood vessel formation is desired, for example, cancer, macular degeneration, diabetic retinopathy and others.

\section{Introduction}

Traditional medicinal plants belong to the characteristics of most cultures on this earth. Medicinal plants helped to secure survival of our ancestors in a noncivilized world, which was not dominated by the technological achievements of the 20th and 21st centuries. Medicinal plants were not only indispensable for as basic health care of indigenous tribes in former ages as modern medicine was not in place. Even nowadays, phytotherapy is still used by a majority of the world's population. Over 50,000 plants would possess therapeutic virtues in the world and about $80 \%$ of human use herbal medicines at least once in their life $[1,2]$. The pharmacological screening of plants is an important mean for the discovery of new, safe, and effective drugs in classical pharmacology [3]. Hence, it comes as no surprise that research on medicinal plants and natural products derived from them experiences a thriving revival in the past years.

Complementary and alternative medicine and traditional medicines are well acknowledged among the general population in industrialized countries $[4,5]$. Many patients use complementary and alternative medicine, frequently without the knowledge of their doctors. Therefore, there is an urgent need for quality-controlled and safe but also effective products from complementary and alternative medicine. Clinical trials and cellular and molecular mechanistic studies on medicinal 
herbs will help to improve their rational use and to better understand their modes of action. This was the motivation for many scientists from pharmacy and pharmacology, including our own group, to investigate the bioactivity of medicinal plants and phytochemicals isolated from them using techniques of molecular pharmacology and molecular biology [6-11]. With a strong commitment to traditional Chinese medicine [12-14] and traditional African medicine in the past years [15-17], we now focus on traditional Korean medicine.

Traditional Korean medicine is widely used in Korea and is the primary health care system for more than $20 \%$ of the population $[18,19]$. Demographic studies confirm that traditional Korean medicine flourishes in modern Korea. One regional survey found that $36 \%$ of the Korean population had used complementary and alternative medicine in a 5-year period, although traditional Korean medicine use was not specified [20]. Forty percent of hypertensive patients used complementary and alternative medicine including traditional Korean medicine after discharge from hospitals [18]. A South Korean national survey was performed among 79\% of people who are older than 18 years old and have health problems within one year. The result showed that $40 \%$ of those did not do anything, 23\% of them visited western doctors' offices or western hospitals, and 19\% used complementary and alternative medicine only (including traditional Korean medicine), with $18 \%$ using both western medical and TKM service [20].

It was reported that excessive angiogenesis is an important factor of the pathogenesis of many industrialized western countries [21]. Plants with anti-angiogenesis properties are therefore of considerable importance for diseases such as cancer, macular degeneration, diabetic retinopathy, and others [22-25].

Based on the antiangiogenic activity of the plant extracts in a modified in vivo chicken chorioallantoic membrane assay, selected phytochemicals were analyzed in more detail. A molecular docking approach was applied to investigate in silico the binding of selected phytochemicals to the vascular endothelial growth factor receptor (VEGFR1, FLT1) as an important angiogenic factor.

As previously shown for other antiangiogenic drugs [26], the microarray-based mRNA expression of VEGFR1/FLT1 and 89 other angiogenesis-regulating genes was correlated to the $\mathrm{IC}_{50}$ values of 60 cell lines of the National Cancer Institute, USA, for selected phytochemicals derived from traditional Korean medicine to identify possible cellular factors associated with their antiangiogenic activity.

\section{Materials and Methods}

2.1. Plant Material and Extraction. Medicinal plants used in the present work were collected at different localities of South Korea and provided by Professor Ik-Soo Lee (College of Pharmacy, Chonnam National University, Gwangju, South Korea). The plants were identified at the national herbarium, where voucher specimens were deposited under the references numbers (see Supplementary Table 1 in Supplementry Materials available online at http://dx.doi.org/10.1155/2013/ 131306). The extraction of the air-dried and powdered plant material was conducted using methanol (HPLC grade) with either ASE 300 (Dionex) or a sonicator (Branson Ultrasonics) at $50^{\circ} \mathrm{C}$. The extracts were then conserved at $4^{\circ} \mathrm{C}$ until further use.

\subsection{Angiogenesis Test}

2.2.1. Cultivation of Quail Eggs. Quail eggs were cultured according to a described method [27]. Briefly, fertilized quail eggs were incubated for $70 \mathrm{~h}$ at $38^{\circ} \mathrm{C}$ and $80 \%$ relative humidity. After $70 \mathrm{~h}$ of incubation the eggs were opened. For this purpose, the eggs were placed in a vertical position to guarantee that the embryo floats in the upper part of the egg. Afterwards, a hole was cut into the top of the egg and the complete content of the egg, was transferred into a Petri dish. By using this method, it could be guaranteed that the albumin gets first into the Petri dish followed by the yolk with the embryo on top without exposing the embryo to shock forces which could damage the vitelline membrane.

\subsubsection{Chicken Chorioallantoic Membrane Assay (CAM Assay).} Plant extracts were tested for their antiangiogenic effects on quail eggs as previously described for chicken eggs with modifications $[28,29]$. Briefly, the explanted embryo was placed in an incubator for $2 \mathrm{~h}$ at $38^{\circ} \mathrm{C}$ to acclimatize it to the new ambience. Subsequently, the test substances were placed on the CAM. Therefore, $2 \%$ agarose solution was prepared and mixed $1: 10$ with the plant extract prior diluted in DMSO $0.1 \%$ final concentration. The final concentration of the extract was $10 \mu \mathrm{g} / \mathrm{mL}$. Pellets with $0.1 \%$ DMSO served as control. The agarose-pellets were then placed on the CAM after they cooled down to room temperature. The Petri dishes with the quail embryos were placed in the incubator again and incubated at $38^{\circ} \mathrm{C}$ and $80 \%$ relative humidity for $24 \mathrm{~h}$ before documenting the effect of the applied substances.

Imaging of the vascularized quail eggs was performed using a digital camera with $3 \mathrm{x}$ magnification objective (Canon eos 500 with a Canon mp-e 652.8 macro objective). For illumination, a mercury arc lamp was used which provided a high fraction of blue and UV light to obtain good contrast values between yolk and vessels. The pictured image section had a size of $5 \times 5 \mathrm{~mm}$. Following image acquisition, quantitative analysis was performed using a routine software which was written in the ImageJ-macro language, then the total small vessel number (or area) was then determined by the system, and the percentage inhibition of vascularization was calculated [30].

2.3. Correlation of Angiogenesis-Regulating Gene Expression with Cytotoxicity of Tumor Cell Lines. The mRNA microarray hybridization of the NCI cell line panel has been described $[31,32]$, and the data has been deposited at the NCI website (http://dtp.nci.nih.gov/). The performance of the COMPARE and hierarchical cluster analyses using mRNA-based microarray data of the database of the National Cancer Institute, USA, has been previously described by us [33]. A set of 89 genes were chosen because of their involvement in angiogenic processes [34]. The microarray data of this set of genes was exemplarily validated by real-time RT-PCR [26]. 


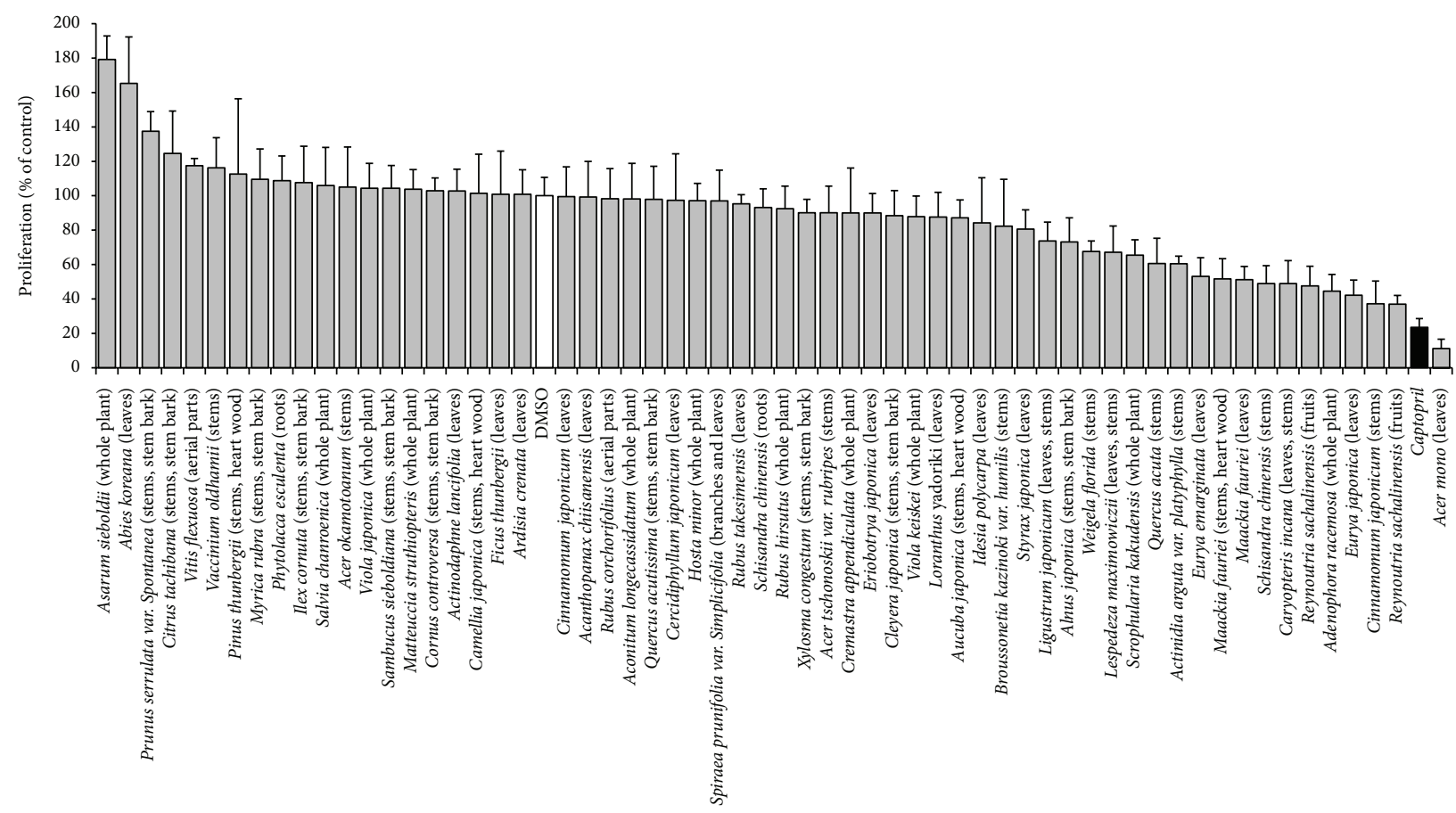

Figure 1: Antiangiogenic effects of the 59 Korean plant extracts $(10 \mu \mathrm{g} / \mathrm{mL})$ on the growth of blood capillaries on the CAM of quail eggs. Mean values \pm SD of each five eggs are shown. DMSO: solvent control (white bar); captopril: positive control (10 $\mu \mathrm{g} / \mathrm{mL}$; black bar).

2.4. Statistics. Pearson's correlation test was used to calculate significance values and rank correlation coefficients as relative measure for the linear dependency of two variables. This test was implemented into the WinSTAT Program (Kalmia). The one-way ANOVA at 95\% confidence level was used for statistical analysis.

2.5. Molecular Docking. Human vascular endothelial growth factor receptor 1 tyrosine kinase domain (VEGFR1-TK) structure was retrieved from PDB database (PDB code: $3 \mathrm{HNG})$, which was submitted in complex with $\mathrm{N}$-(4chlo-rophenyl)-2-[(pyridin-4-ylmethyl)amino]benzamide). Chem-Spider and PubChem were referred for the 3D structures of control drugs and the Korean medicine compounds. Molecular docking calculations were performed with AutoDock4 [35]. Axitinib, which is an antiangiogenic compound and a known VEGFR1 and VEGFR2 inhibitor, was selected as the control drug to compare the binding energies and the docking sites of the candidate ligands. The residues of VEGFR1, which the N-(4-chlorophenyl)2-[(pyridin-4-ylmethyl)amino]benzamide and control drugs in the literature make hydrogen bond with, were selected for the defined docking. Drug binding residues of VEGFR1 were identified as Val841, Ala859, Lys861, Glu878, Leu882, Val892, Val909, Cys912, Leu1029, and Asp1040. Furthermore, VEGFR2 PDB structure (PDB code: 3U6J), which was submitted in complex with a pyrazolone inhibitor (N-\{4-[(6,7-dimethoxyquinolin-4-yl)oxy]-3-fluorophenyl\}-1, 5-dim-ethyl-3-oxo-2-phenyl-2,3-dihydro-1H-pyrazole-4-carboxamide), was used. The drug interaction residues for VEGFR2 were Leu 840, Ala 866, Lys 868, Leu 889, Ile 892,
Phe 918, Cys 919, Leu 1019, Leu 1035, Cys 1045, Asp 1046, and Phe 1047.

Grid maps were created covering those residues. For the docking calculations, the number of energy evaluations was set to 2,500,000 and the number of runs was set to 100. The lamarckian Genetic Algorithm was chosen for the docking calculations. For the visualization of the docking results, AutoDock Tools and Visual Molecular Dynamics were used. The surface representation image showing the binding pocket of human VEGFR1-TK was made with VMD software developed with NIH support by the theoretical and computational biophysics group at the Beckman Institute, University of Illinois at Urbana-Champaign.

\section{Results}

3.1. Antiangiogenic Activity In Vivo. Out of 59 plant extracts tested in the CAM assay, seven samples showed significant inhibition $(>50 \%)$ of angiogenesis. They include extracts from Acer mono leaves, Reynoutria sachalniensis fruits, Cinnamomum japonicum stems, Eurya japonica leaves, Adenophora racemosa whole plant, Caryopteris incana leavesstems, and Schisandra chinensis stems (Figure 1).

Representative images of the effect of antiangiogenic Korean plant extracts $(10 \mu \mathrm{g} / \mathrm{mL})$ on the growth of blood capillaries on the CAMs of quail eggs are shown in Figure 2.

3.2. Correlation of $m R N A$ Expression of Angiogenic Genes with $I_{50}$ Values of NCI Cell Lines for Phytochemicals from Korean Plants. As a next step, we searched the literature on chemical constituents of antiangiogenic Korean plants (Table 1). 


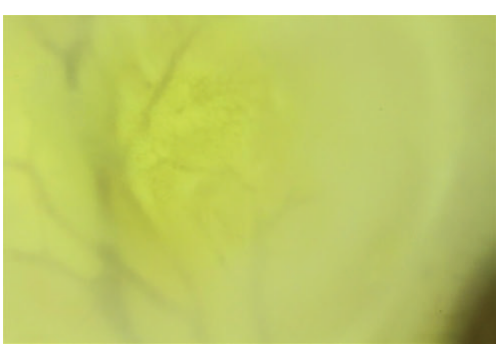

(a)

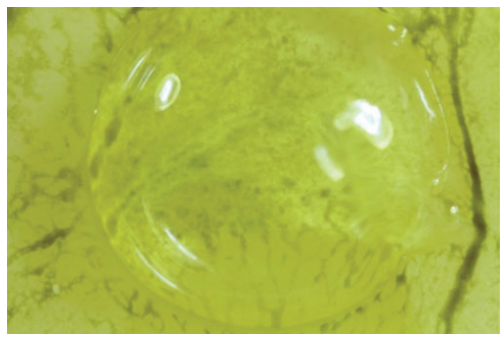

(d)

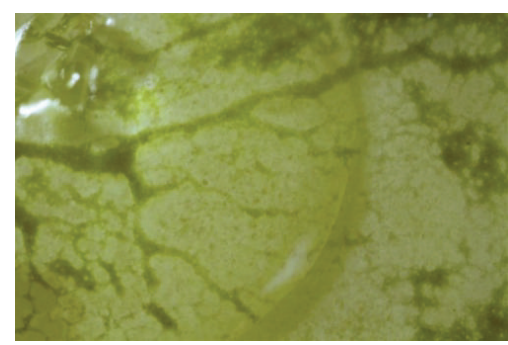

(g)

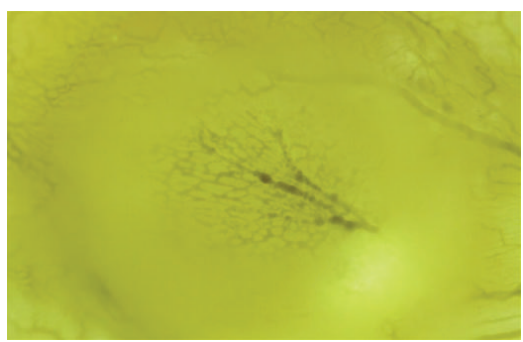

(b)

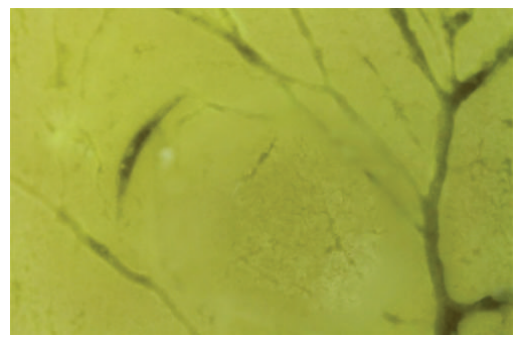

(e)

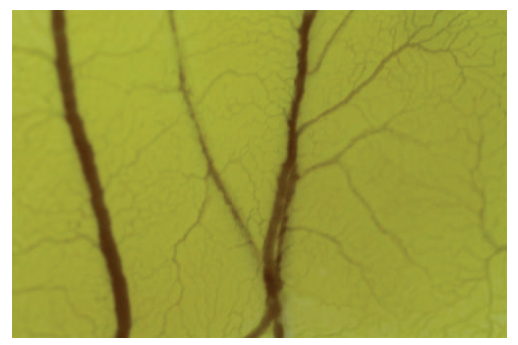

(h)

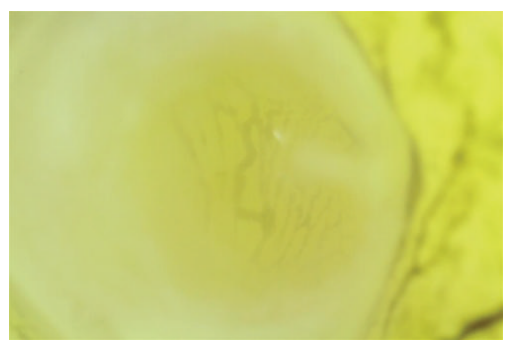

(c)

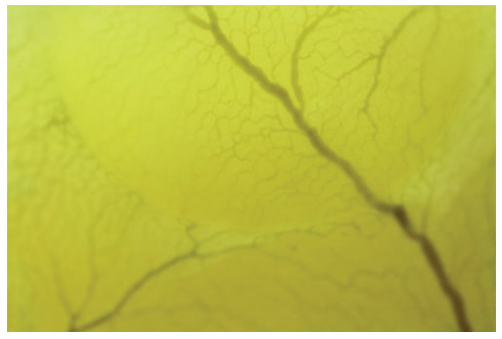

(f)

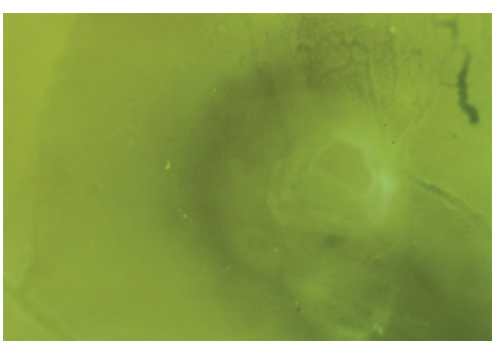

(i)

FIGURE 2: Representative images of the effect of antiangiogenic Korean plant extracts $(10 \mu \mathrm{g} / \mathrm{mL})$ on the growth of blood capillaries on the CAM of quail eggs. The tested extracts were from: Acer mono leaves (a); Reynoutria sachalniensis fruits (b); Cinnamomum japonicum stems (c); Eurya japonica leaves (d); Adenophora racemosa whole plant (e); Caryopteris incana leaves stems (f); Schisandra chinensis stems (g); DMSO or solvent control (h); captopril as positive control (i).

Then, we mined the NCI database for these compounds (http://dtp.nci.nih.gov/). Five compounds were found in the database and were exemplarily selected as possible antiangiogenic candidate compounds, that is, verbascoside, apigenin, emodin, resveratrol, and eriodictyol tetraacetate (Figure 3). Axitinib is a known VEGFR inhibitor and served as control drug. The average $\mathrm{IC}_{50}$ values over the entire range of NCI cell lines are shown in Figure 4.

The $\mathrm{IC}_{50}$ values of these phytochemicals were correlated with the baseline mRNA expression levels of 89 genes involved in angiogenic pathways for the NCI panel of tumor cell lines by the Pearson rank correlation test. Only those genes, whose expression correlated with $R>0.3$ or $R<-0.3$ with the $\mathrm{IC}_{50}$ values of the five compounds were considered for further analyses (Table 2).

The gene expressions of these genes were then subjected to hierarchical cluster analysis. The dendrograms for verbascoside, apigenin, and emodin are shown in Figure 5. To investigate whether these gene expression profiles contain relevant information, we correlated them with the distribution of $\mathrm{IC}_{50}$ values for these three compounds of the cell lines. The $\mathrm{IC}_{50}$ values themselves were not used for generation of the cluster dendrograms. Therefore, we could address the question whether or not the gene expressions alone predicted the response of the cell line panel to these phytochemicals. As shown in Table 3, the distribution of the cell lines sensitive or resistant to the three natural products was significantly different, indicating that these angiogenesis-regulating genes indeed determined the response of tumor cells to verbascoside, apigenin, and emodin. These analyses were also performed for resveratrol and eriodictyol tetraacetate, but significant relationships were not found, indicating that these gene expression profiles were not predictive for response of tumor cell lines to these two compounds (Table 3 ).

\subsection{Molecular Docking of Phytochemicals from Korean Plants} to VEGFR1 and VEGFR2. Since antiangiogenic effects may not only be mediated by up- or downregulation of gene expressions but also by direct binding to angiogenic target molecules, we addressed the question whether the five selected phytochemicals may bind to VEGFR1 and VEGFR2. For this reason, we applied an in silico molecular docking approach. As a control drug, we used axitinib, a synthetic 


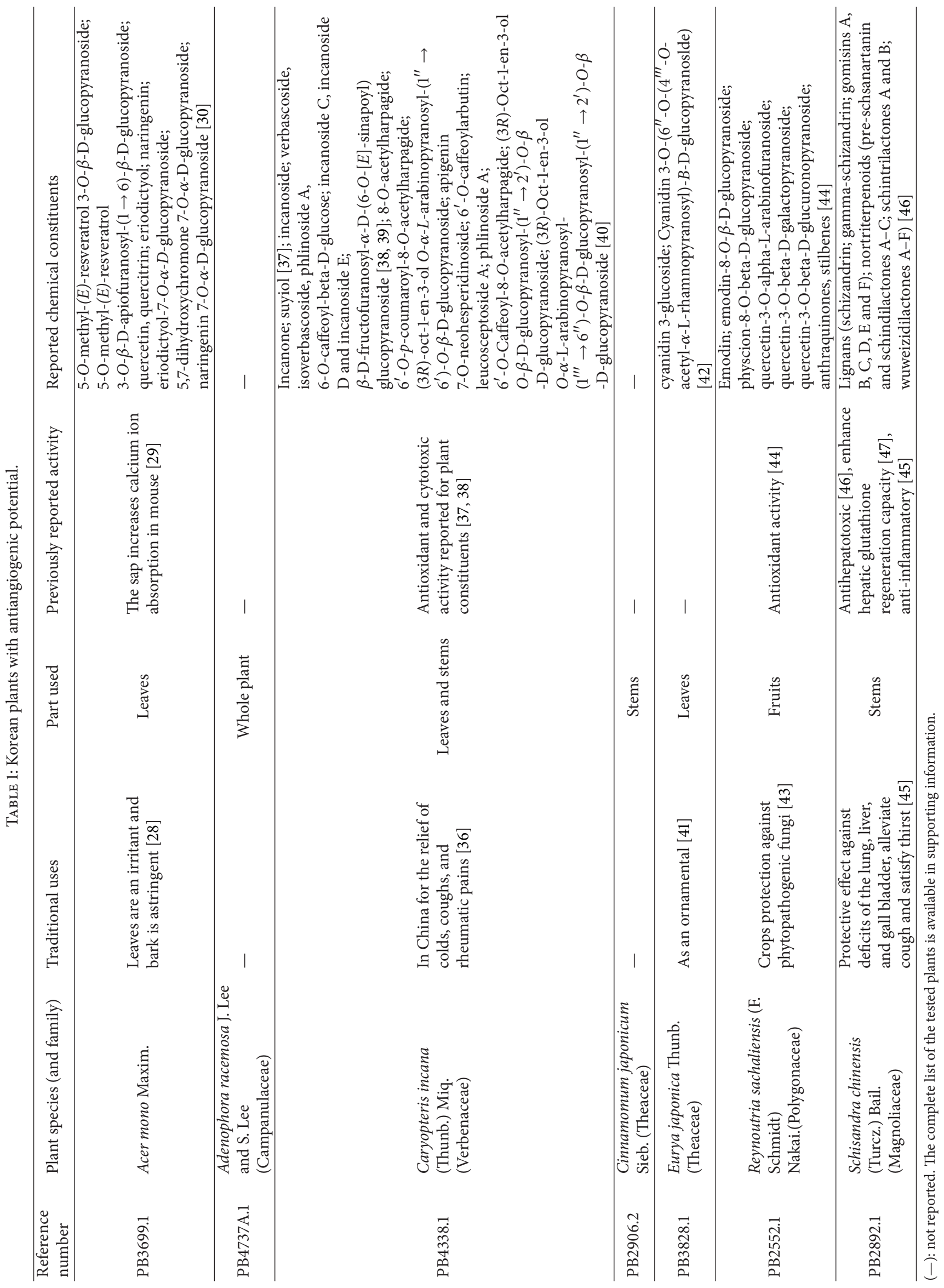




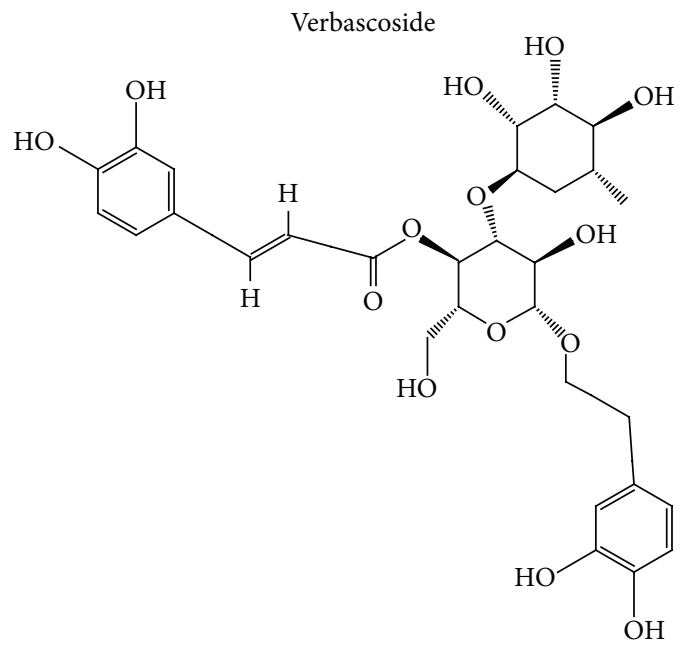<smiles>[R][Co]#[X]</smiles><smiles>O=c1cc(-c2ccc(O)cc2)oc2cc(O)cc(O)c12</smiles><smiles>CC(=O)Oc1cc(OC(C)=O)c2c(c1)OC(c1ccc(OC(C)=O)c(OC(C)=O)c1)CC2=O</smiles><smiles>Cc1cc(O)c2c(c1)C(=O)c1cc(O)cc(O)c1C2=O</smiles><smiles>CNC(=O)c1ccccc1Sc1ccc2c(C=Cc3ccccn3)n[nH]c2c1</smiles>

FIGURE 3: Chemicals structures of selected phytochemicals derived from Korean medicinal plants.

TABLE 2: Expression of angiogenesis-regulating genes correlating with $\mathrm{IC}_{50}$ values of selected phytochemicals in the NCI panel of tumor cell lines $(R>0.3 ; R<-0.3)$. The full names of the abbreviations given are listed in Supplementary Table 1.

\begin{tabular}{lcc}
\hline Compound & Direct correlation with gene expression $(R>0.3)$ & Inverse correlation with gene expression $(R<-0.3)$ \\
\hline Verbascoside & $M P D Z, M M R N$, F3, PECAM1, DDAH2, and NOTCH3, DVL3 & NOS2A, C1QR1, PML, and STC1 \\
Emodin & $P E C A M 1$, NID2 & TIMP3, SNX17, TFPI2, SPR, and ANG \\
Apigenin & NRCAM & FGR2 \\
Eriodictyol tetraacetate & FGFR2, SST, TEK, PML, and ANGPTL3 & EFEMP1, C1QR1, PECAM1, STC1, and TGFB1 \\
Resveratrol & TIMP3, EPhA2, PLT, PIN, and COL4A2 & FN1, PECAM1, PML, ABCG1, and CXCR4 \\
Axitinib (control drug) & $C O L 5 A 1, B P R 2$ & THBS4 \\
\hline
\end{tabular}

small molecule inhibitor which binds to defined pharmacophores of VEGFR1 and VEGFR2. Remarkably, all five natural products bound to the same pharmacophores as axitinib, albeit at lower binding affinities (Table 4). Eriodictyol tetraacetate showed the lowest binding energy for both VEGFR1 and VEGFR2. Quercetin might be an efficient VEGFR1 inhibitor since it made hydrogen bond with drug binding residues (Glu878 and Cys912) with low binding energy. Apigenin was observed to make hydrogen bond with drug binding residues on VEGFR1 (Glu878, Cys912, and Asp1040) and VEGFR2 (Lys868, Cys919, Asp1046) like axitinib. Thus, apigenin seems to be a promising candidate as an antiangiogenic compound. Moreover, it was found that resveratrol interacted with VEGFR1 and VEGFR2 with high affinity and made hydrogen bond with drug binding residues (Glu878 and Cys912 on VEGFR1, Lys868, Cys919, and Asp1046 on VEGFR2). Besides, verbascoside bound to VEGFR2 (-9.99 kcal/mol) with higher affinity than VEGFR1 $(6.93 \mathrm{kcal} / \mathrm{mol})$. Emodin showed moderately low binding energies compared to other compounds. 
TABLE 3: Separation of clusters of the NCI cancer cell lines obtained by hierarchical cluster analysis for selected phytochemicals from antiangiogenic plants derived from traditional Korean medicine. The $\log _{10} \mathrm{IC}_{50}$ median values (M) of each compound were used as cutoff values to define cell lines as being sensitive or resistant. $P>0.05$ was considered as not significant $\left(\chi^{2}\right.$ test).

\begin{tabular}{|c|c|c|c|c|}
\hline Compounds & Clusters & Sensitive & Resistant & $P$-value ( $\chi^{2}$ test $)$ \\
\hline \multirow{5}{*}{ Verbascoside } & Partition* & $\leq-4.278$ & $>-4.278$ & \multirow{5}{*}{$P=3.35497 \times 10^{-4}$} \\
\hline & Cluster 1 & 3 & 14 & \\
\hline & Cluster 2 & 4 & 9 & \\
\hline & Cluster 3 & 9 & 1 & \\
\hline & Cluster 4 & 8 & 1 & \\
\hline \multirow{6}{*}{ Emodin } & Partition* ${ }^{*}$ & $\leq-4.607$ & $>-4.607$ & \multirow{6}{*}{$P=0.0142$} \\
\hline & Cluster 1 & 7 & 2 & \\
\hline & Cluster 2 & 5 & 1 & \\
\hline & Cluster 3 & 8 & 15 & \\
\hline & Cluster 4 & 8 & 4 & \\
\hline & Cluster 5 & 1 & 6 & \\
\hline \multirow{5}{*}{ Apigenin } & Partition* & $\leq-4.543$ & $>-4.543$ & \multirow{5}{*}{$P=0.02628$} \\
\hline & Cluster 1 & 2 & 9 & \\
\hline & Cluster 2 & 5 & 4 & \\
\hline & Cluster 3 & 9 & 1 & \\
\hline & Cluster 4 & 6 & 7 & \\
\hline \multirow{3}{*}{ Eriodictyol tetraacetate } & Partition & $\leq-4.358$ & $>-4.358$ & \multirow{3}{*}{ n.s. ${ }^{* *}$} \\
\hline & Cluster 1, 2, 3 & 6 & 2 & \\
\hline & Cluster 4 & 2 & 5 & \\
\hline \multirow{6}{*}{ Resveratrol } & Partition* ${ }^{*}$ & $\leq-4.223$ & $>-4.223$ & \multirow{6}{*}{ n.s. ${ }^{* *}$} \\
\hline & Cluster 1 & 3 & 2 & \\
\hline & Cluster 2 & 9 & 5 & \\
\hline & Cluster 3 & 5 & 4 & \\
\hline & Cluster 4 & 3 & 10 & \\
\hline & Cluster 5 & 4 & 3 & \\
\hline \multirow{4}{*}{ Axitinib (control drug) } & Partition* & $<-5.015$ & $>-5.015$ & \multirow{4}{*}{ n.s. ${ }^{* *}$} \\
\hline & Cluster 1 & 10 & 15 & \\
\hline & Cluster 2 & 4 & 6 & \\
\hline & Cluster 3 & 15 & 8 & \\
\hline
\end{tabular}

${ }^{*} \log _{10} \mathrm{IC}_{50}(\mathrm{M})$

${ }^{* *}$ n.s.: not significant $(P>0.05)$.

The binding of the five phytochemicals and axitinib to VEGFR1 is shown in Figure 6. Similar binding modes were found for VEGFR2 (data not shown).

\section{Discussion}

4.1. Antiangiogenic Activity In Vivo. Antiangiogenic compounds are gaining more and more interest as a new approach in the prevention and treatment of cancer and inflammatory diseases [48]. The CAM assay is a sensitive, easily feasible, and cheap in vivo test for investigations of the antiangiogenic potential of individual compounds and plant extracts [49]. The assay does not only provide information on the efficacy of test samples in vivo but also on their toxicity in vivo.

To the best of our knowledge, their antiangiogenic property is being reported here for the first time. The best antiangiogenic effect was recorded with the extract from Acer mono (11.14\% proliferation), this activity being better than that of captopril (23.54\% proliferation), highlighting its possible importance in cancer therapy. Captopril served as control drug, since its antiangiogenic activity is well known and the drug also inhibited angiogenesis in the CAM-assay [50, 51]. Schisandra chinensis exhibited a good but different extent of angiogenesis inhibition with both leaves and stems extracts, strengthening the hypothesis that it is necessary to screen various plant organs when evaluating their pharmacological activities. A comparison of our Korean plant extracts showed that there was no correlation between cytotoxicity and antiangiogenic activity [52]. Therefore, these extracts might not only be used to inhibit angiogenesis in tumors but also for treatment of noncancerous diseases such as diabetic retinopathy or macular degeneration. It has been shown during the past years that therapeutic antibodies which target VEGF are not only active in cancer but are also a considerable 
TABLE 4: In silico molecular docking to VEGFR1 and VEGFR2 of selected phytochemicals from antiangiogenic plants derived from traditional Korean medicine. (Residues marked bold are the drug binding residues).

\begin{tabular}{|c|c|c|c|c|c|}
\hline Receptors & Compounds & $\begin{array}{l}\text { Lowest energy of } \\
\text { docking (kcal/mol) }\end{array}$ & $\begin{array}{l}\text { Mean binding } \\
\text { energy (kcal/mol) }\end{array}$ & $\begin{array}{l}\text { Residues involved hydrogen bond } \\
\text { interaction with the ligand }\end{array}$ & $\begin{array}{c}\text { Number of residues } \\
\text { involved in } \\
\text { hydrophobic } \\
\text { interaction with } \\
\text { ligand }\end{array}$ \\
\hline \multirow{7}{*}{ VEGFR1 } & Axitinib (control drug) & -12.71 & -12.38 & $\begin{array}{l}\text { Glu 878, Cys 912, Glu 910, Asp } \\
1040\end{array}$ & 12 \\
\hline & Eriodictyol tetraacetate & -9.92 & -9.27 & Asp 1040 & 14 \\
\hline & Quercetin & -9.01 & -8.51 & Glu 878, Glu 910, Cys 912 & 9 \\
\hline & Apigenin & -8.85 & -8.56 & Glu 878,Cys 912, Asp 1040 & 11 \\
\hline & Resveratrol & -7.89 & -7.72 & Lys 861, Glu 878,Cys 912 & 10 \\
\hline & Emodin & -7.30 & -7.30 & Leu 833, Glu 910, Cys 912 & 10 \\
\hline & Verbascoside & -6.93 & -4.95 & Arg 1021, Asp 1022, Asp 1040 & 11 \\
\hline \multirow{7}{*}{ VEGFR2 } & Axitinib (control drug) & -12.39 & -12.20 & Glu 917, Asp 1046 & 14 \\
\hline & Eriodictyol tetraacetate & -10.56 & -9.85 & Ala 1050 & 18 \\
\hline & Verbascoside & -9.99 & -5.33 & His 816, Thr 916, Asp 1046, Ala 1050 & 19 \\
\hline & Apigenin & -9.04 & -9.01 & Lys 868, Cys 919, Asp 1046 & 11 \\
\hline & Quercetin & -8.29 & -8.18 & Ala 881, Glu 885, Ile 1025, Ile 1044 & 11 \\
\hline & Resveratrol & -8.15 & -8.05 & Lys 868, Cys 919, Asp 1046 & 9 \\
\hline & Emodin & -7.63 & -7.35 & Ile 1025, Asp 1046 & 9 \\
\hline
\end{tabular}

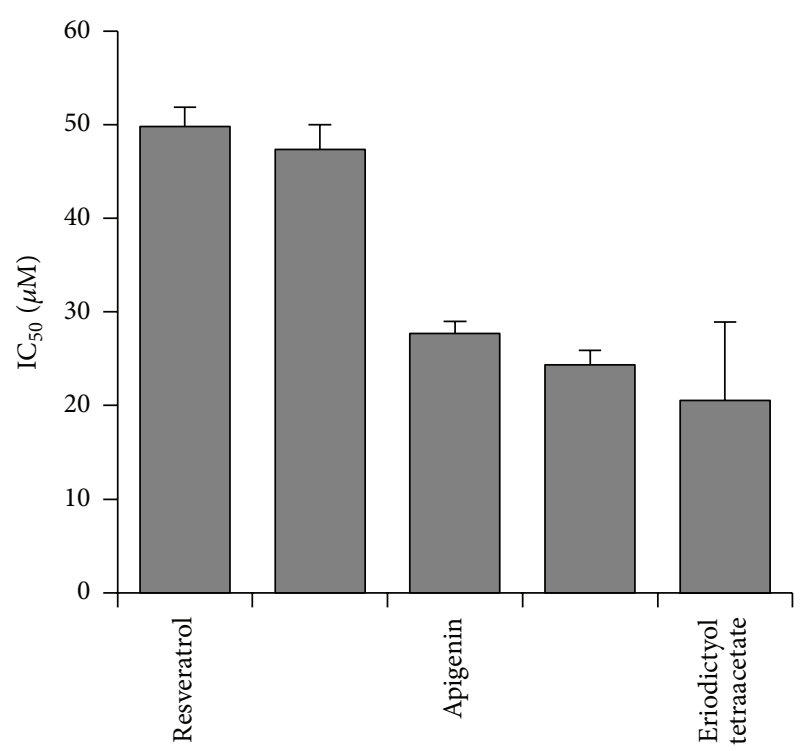

FIGURE 4: Cytotoxic activity of selected phytochemicals derived from Korean medicinal plants for tumor cell lines from the NCI cell line panel.

potential for ophthalmologic applications [23]. It is reasonable to speculate that plant extracts with antiangiogenic properties may not only be candidate for cancer therapy but also for therapeutic applications in ophthalmology.

4.2. Microarray-Based Gene Expression Profiling. In the present investigation, the $\mathrm{IC}_{50}$ profiles of five phytochemicals for the panel of 60 cell lines of the National Cancer Institute (NCI), USA, were correlated with the microarray-based expression profiles of the cell lines. The intention was to identify molecular determinants which predict sensitivity or resistance of tumor cells to these compounds. This concept was developed in the 1990s at the Developmental Therapeutics Program of the NCI to extract meaningful information of large-scale drug screenings [53]. During the past years, this concept provided a fertile ground to unravel mechanisms of action of new drugs and to use gene expression profiles for the prediction of chemosensitivity of tumor cells [54-56]. We applied this approach to gain insight of determinants of activity of natural products derived from traditional Chinese medicine, for example, homoharringtonine, artemisinin, cantharidin, arsenic trioxide, and others [36-40,57].

In the present investigation, we focused on compounds derived from traditional Korean medicine. It was a striking feature that genes with diverse functions correlated with the response of the NCI cell lines to phytochemicals (verbascoside, apigenin, emodin, quercetin, eriodictyol, and resveratrol). This result may be taken as a hint that these natural products affect several targets and intracellular signaling pathways. This hypothesis is supported by similar observations of other authors.

Emodin inhibits tumor growth in vitro and in vivo [41, 42]. Several proteins involved in angiogenesis have been associated with this effect, including matrix metalloproteinases 2 and 9, basic fibroblast growth factor, urokinase plasminogen activator, plasminogen inhibitor 1 , the extracellular signalregulated kinases 1 and $2(\mathrm{ERK} 1 / 2)$, and the chemokine CXCR4 receptor $[41,42,58,59]$. Furthermore, emodin inhibits the phosphorylation of the VEGF receptors 1, 2, and 3 [60]. 

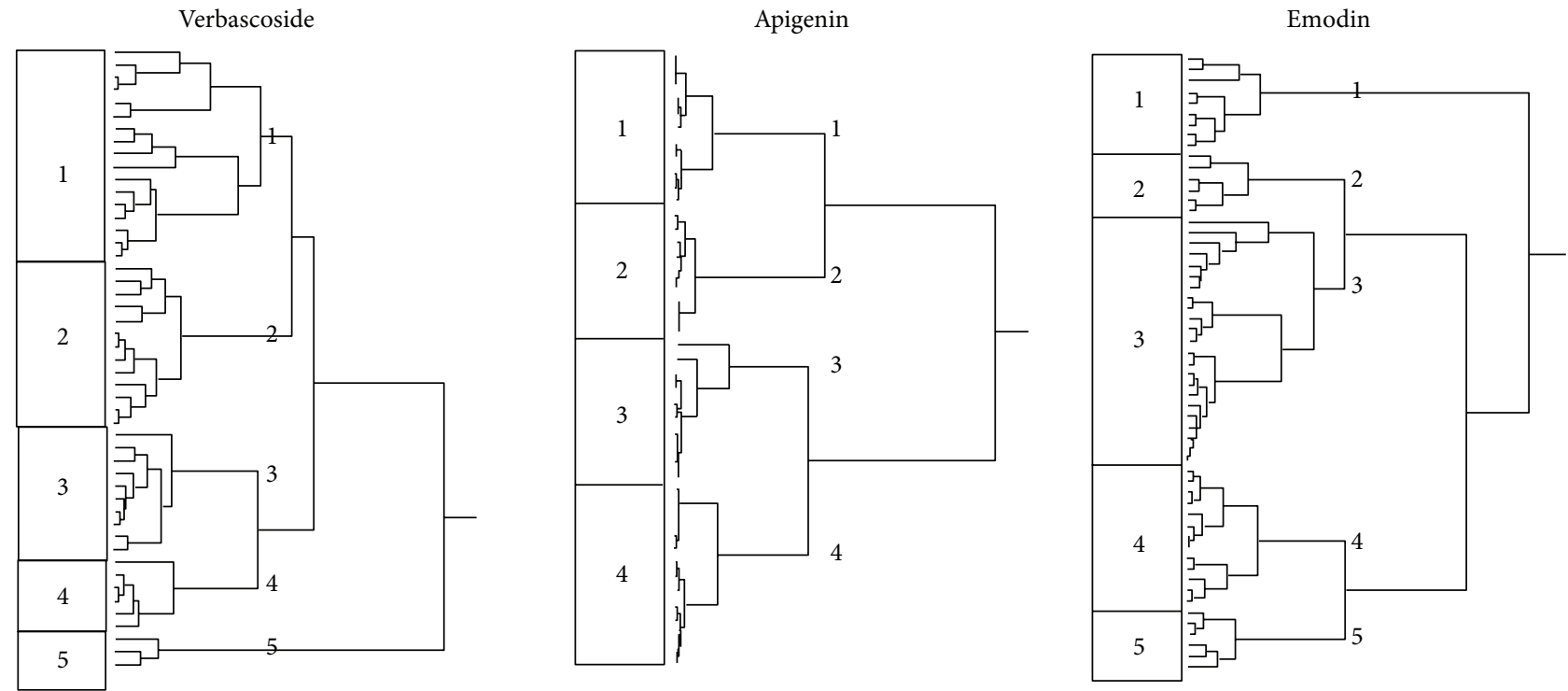

FIGURE 5: Dendrograms obtained by hierarchical cluster analysis of microarray-based expressions of angiogenesis-regulating genes for selected phytochemicals derived from Korean medicinal plants for tumor cell lines from the NCI cell line panel. The dendrograms were obtained by clustering using the WARD method. Extended versions of these dendrograms showing the exact positions of each cell line are included as Supplementary Material.

Apigenin inhibits angiogenesis by inhibiting VEGF and HIF-1 expression via the PI3 K/AKT/P70S6 K1 and HDM2/ p53 pathways $[61,62]$. Further antiangiogenic mechanisms are downregulation of type I collagen, vimentin, matrix metalloproteinase 8 , and of the cytokine IL6/STAT3 pathway $[63,64]$.

Angiogenesis is inhibited by resveratrol both in vitro and in vivo [65-67]. Several mechanisms have been unraveled, for example, downregulation and/or inhibition of VEGF, HIF$1 \alpha$, Flk-1, and Src $[68,69]$. Various signaling pathways contribute to inhibition of angiogenesis such as the eukaryotic elongation factor-2 kinase-regulated pathway, the GSK3 $\beta$ / $\beta$-catenin/TCF-dependent pathway, NF- $\kappa$ B-related signaling, and cytokine signaling (IL8/CXCL8) [43, 44, 70, 71]. The antiangiogenic activity of verbascoside and eriodictyol tetraacetate has not been described yet.

Microarray analyses have been previously performed for emodin, verbascoside, and resveratrol and a huge number of genes have been found to be regulated by treatment with these compounds [45-47, 72-74]. Together with the microarray data of the present investigation, these results further emphasize the multifactorial activity of natural products. While some scientists from conventional academic medicine have called natural products as "dirty drugs" for their multiple modes of action, the past years of intense research on synthetic and monospecific drugs showed that synthetic drugs are not superior. Tumor cells readily develop resistance to monospecific drugs, for example, by point mutations in the corresponding target proteins preventing drug binding, by downregulation of target gene expression, or by activation of alternative signaling routes and bypassing of inhibited pathways [75]. The probability is much less that tumor cells escape treatment with multifactorial drugs, since resistance to one mode of drug action does not affect the drug's activity on other cellular signaling pathways. The fact that organisms developed rather multi- than monotarget compounds during evolution of life on earth may be taken as a clue that the concept of multitargeted therapy is superior $[76,77]$.

4.3. Molecular Docking of VEGFR1 and VEGFR2. Antiangiogenic compounds may not only exert their blood vessel inhibiting effects by up- or downregulation of angiogenesisregulating genes, but also by targeting and binding to key regulators of angiogenesis. The specific targeting of growth factor receptors by therapeutic antibodies and small molecules is currently one of the most thriving fields in drug development with a plethora of new drugs on the market. This is also true for antiangiogenic therapies [22]. VEGFRs are exquisite targets to inhibit angiogenesis. Inhibition of the tyrosine kinase activity of VEGFR by small molecules leads to blockage of VEGFR-related downstream-signaling pathways, hence, inhibition of blood vessel sprouting.

The number of VEGFR inhibitors was steadily increasing over the past few years [78]. One of them is axitinib, which specifically binds to all three VEGF receptors, VEGFR1, VEGFR2, and VEGFR3 [79, 80]. Therefore, this drug served as control for our bioinformatical docking studies. The idea was to investigate whether or not the five selected phytochemicals from Korean plants might bind to the same pharmacophore as axitinib. As the crystal structure of VEGFR3 was not available in the PDB database, we only analyzed VEGFR1 and VEGFR2. As expected, axitinib was predicted to bind with high affinity to both receptors, which is indicated by low free binding energies $(<-12 \mathrm{kcal} / \mathrm{mol})$. Molecular docking of verbascoside, apigenin, emodin, quercetin, eriodictyol 


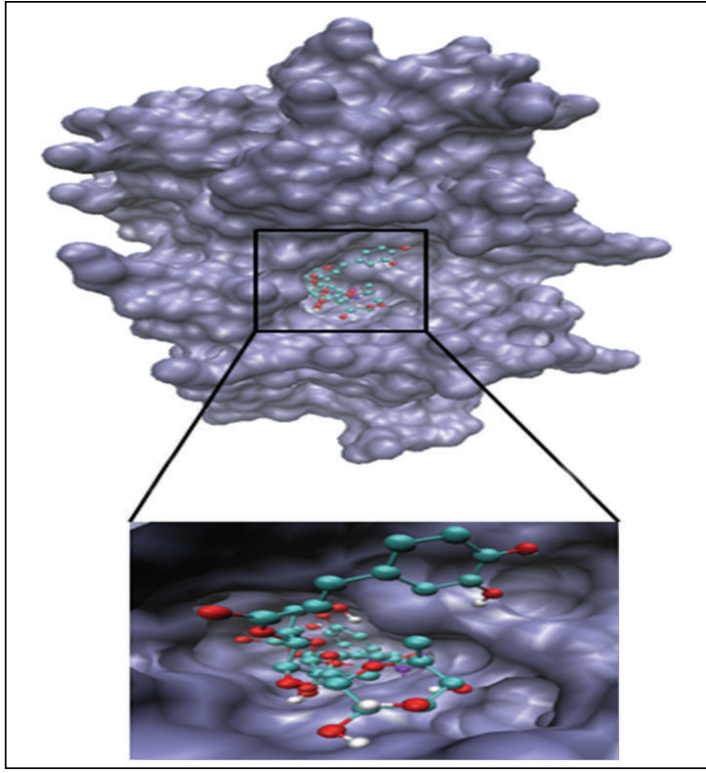

(a)

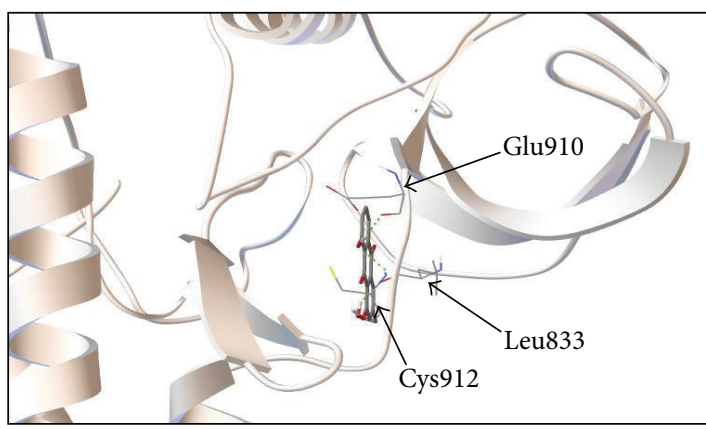

(d)

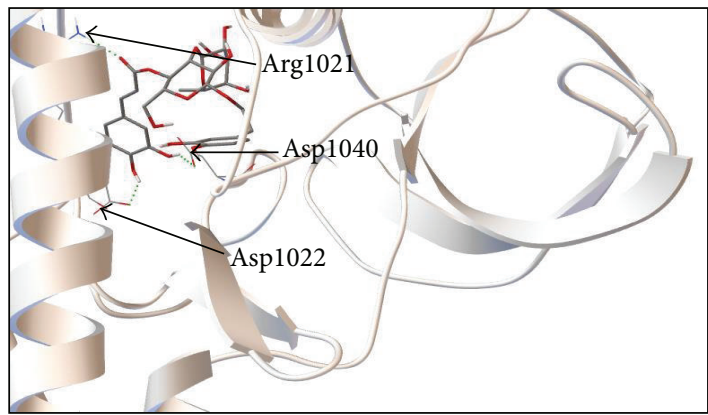

(f)

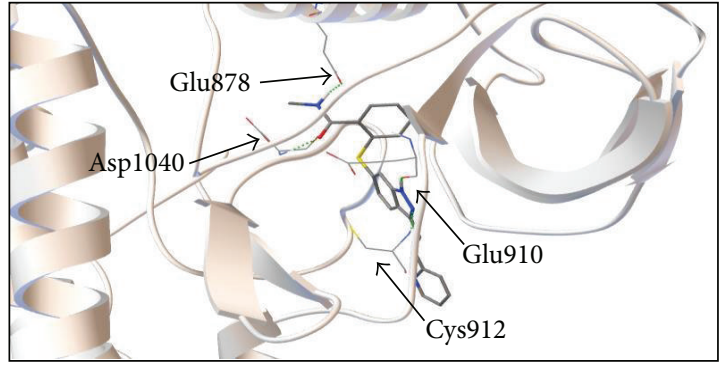

(b)

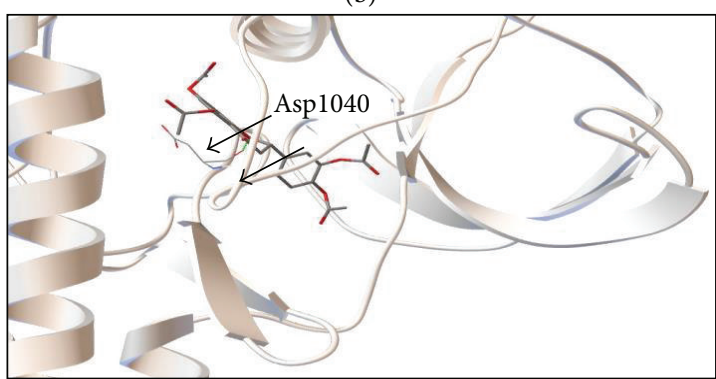

(c)

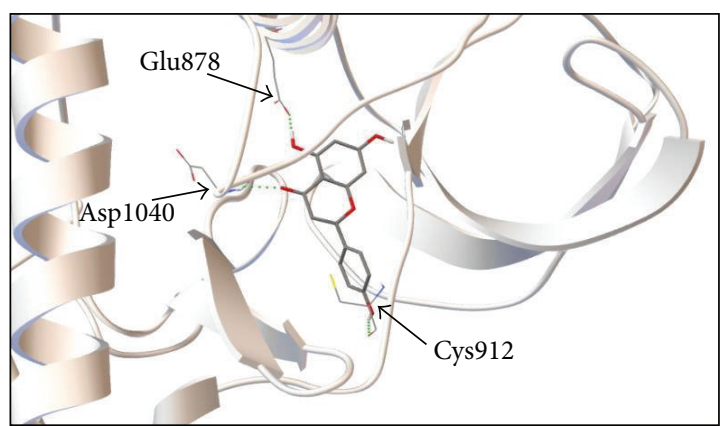

(e)

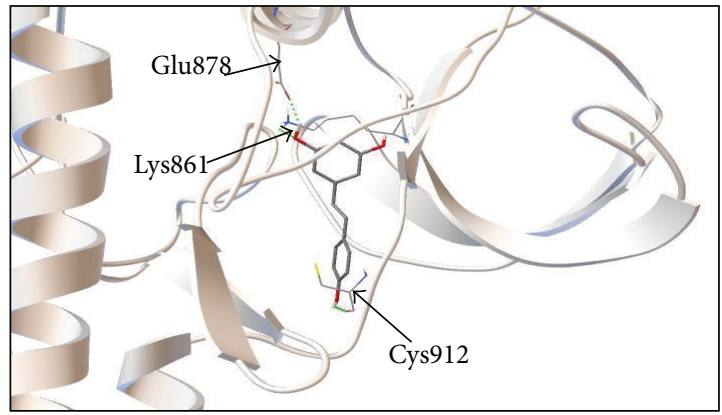

(g)

FIGURE 6: Docking studies of candidate antiangiogenic compounds. (a) Docking of 6 compounds into the binding site of VEGFR1-TK (PDB code: 3 HNG in blue surface representation). The compounds occupy the same binding site as axitinib, a known antiangiogenic compound (in violet). Docked structure of axitinib (b), eriodictyol tetraacetate (c), emodin (d), apigenin (e), verbascoside (f), and resveratrol (g) in VEGFR1-TK binding pocket. The residues involved in hydrogen bond interaction are labeled, and hydrogen bonds are shown as green dots. Axitinib is a known VEGFR-TK inhibitor and was used as control drug.

tetraacetate, and resveratrol yielded free binding energies in a range from -6 to $-9 \mathrm{kcal} / \mathrm{mol}$. This indicates that these phytochemicals may bind to the receptors at lower affinity than axitinib. It can be speculated that these compounds efficiently inhibit angiogenesis by combining different mechanisms, such as VEGFR binding as well as up/downregulation of angiogenic genes and proteins. Therefore, these natural products may be efficient angiogenesis inhibitors, even if they bind with lower affinities to VEGF receptors than axitinib. For drug development, these phytochemicals may serve as lead compounds to synthesize novel derivatives with improved binding properties to VEGF receptors. 


\section{Conclusion}

We estimate medicinal plants in general and especially plants from traditional Korean medicine as valuable and indispensable resources for the development of new drugs and the rational use of phytotherapy. This point of view is supported by a comprehensive survey of the NCI, USA, showing that the vast majority of clinically established cancer drugs during the past three decades were based on natural products [81]. It can be expected that natural products and evidence-based complementary and alternative therapies such as inhibition of angiogenesis by Korean medicinal plants will lead to considerably improve the treatment of patients in the future.

\section{Conflict of Interests}

No potential conflict of interests was disclosed.

\section{Authors' Contribution}

Ean-Jeong Seo and Victor Kuete contributed equally.

\section{Acknowledgments}

The authors are thankful to Mrs. Christine Köppel for her technical assistance performing the antiangiogenesis assays and Mrs. Ilona Zirbs for her secretarial support.

\section{References}

[1] D. S. Bhakuni, M. Bittner, C. Marticorena et al., "Screening of Chilean plants for antimicrobial activity," Lloydia, vol. 37, no. 4, pp. 621-632, 1974.

[2] N. R. Farnsworth, O. Akerele, and A. S. Bingel, "Medicinal plants in therapy," Bulletin of the World Health Organization, vol. 63, no. 6, pp. 965-981, 1985.

[3] Y. Feng, N. Wang, M. Zhu, Y. Feng, H. Li, and S. Tsao, "Recent progress on anticancer candidates in patents of herbal medicinal products," Recent Patents on Food, Nutrition \& Agriculture, vol. 3, no. 1, pp. 30-48, 2011.

[4] O. Olaku and J. D. White, "Herbal therapy use by cancer patients: a literature review on case reports," European Journal of Cancer, vol. 47, no. 4, pp. 508-514, 2011.

[5] M. Frass, R. P. Strassl, H. Friehs, M. Müllner, M. Kundi, and A. D. Kaye, "Use and acceptance of complementary and alternative medicine among the general population and medical personnel: a systematic review," Ochsner Journal, vol. 12, no. 1, pp. 45-56, 2012.

[6] T. Efferth, "Personalized cancer medicine: from molecular diagnostics to targeted therapy with natural products," Planta Medica, vol. 76, no. 11, pp. 1143-1154, 2010.

[7] T. Efferth, "Stem cells, cancer stem-like cells, and natural products," Planta Medica, vol. 78, no. 10, pp. 935-942, 2012.

[8] S. Sertel, P. K. Plinkert, and T. Efferth, "Natural products derived from traditional Chinese medicine as novel inhibitors of the epidermal growth factor receptor," Combinatorial Chemistry and High Throughput Screening, vol. 13, no. 10, pp. 849-854, 2010.

[9] M. Youns, J. D. Hoheisel, and T. Efferth, "Toxicogenomics for the prediction of toxicity related to herbs from traditional
Chinese medicine," Planta Medica, vol. 76, no. 17, pp. 2019-2025, 2010.

[10] T. Efferth and B. Kaina, "Toxicities by herbal medicines with emphasis to traditional Chinese medicine," Current Drug Metabolism, vol. 12, no. 10, pp. 989-996, 2011.

[11] T. Eichhorn and T. Efferth, "P-glycoprotein and its inhibition in tumors by phytochemicals derived from Chinese herbs," Journal of Ethnopharmacology, vol. 141, no. 2, pp. 557-570, 2012.

[12] T. Efferth, P. C. H. Li, V. S. B. Konkimalla, and B. Kaina, "From traditional Chinese medicine to rational cancer therapy," Trends in Molecular Medicine, vol. 13, no. 8, pp. 353-361, 2007.

[13] T. Efferth, Y.-J. Fu, Y.-G. Zu, G. Schwarz, V. S. B. Konkimalla, and M. Wink, "Molecular target-guided tumour therapy with natural products derived from Traditional Chinese Medicine," Current Medicinal Chemistry, vol. 14, no. 19, pp. 2024-2032, 2007.

[14] M. Youns, J. D. Hoheisel, and T. Efferth, "Traditional Chinese Medicines (TCMs) for molecular targeted therapies of tumours," Current Drug Discovery Technologies, vol. 7, no. 1, pp. 37-45, 2010.

[15] V. Kuete and T. Efferth, "Cameroonian medicinal plants: pharmacology and derived natural products," Frontiers in Pharmacology, vol. 1, no. 123, pp. 1-19, 2010.

[16] V. Kuete and T. Efferth, "Pharmacogenomics of Cameroonian traditional herbal medicine for cancer therapy," Journal of Ethnopharmacology, vol. 137, no. 1, pp. 752-766, 2011.

[17] H. Khalid, W. E. Abdalla, H. Abdelgadir, T. Opatz, and T. Efferth, "Gems from traditional north-African medicine: medicinal and aromatic plants from Sudan," Natural Products and Bioprospecting, vol. 2, no. 3, pp. 92-103, 2012.

[18] Y. S. Cheong, E. W. Park, S. M. Yoo et al., "Use of traditional medicine and folk remedies in hypertensive patients: based on Cheonan practice-based research network," Journal of the Korean Academy of Family Medicine, vol. 19, no. 2, pp. 141-149, 1998.

[19] C. D. Hong, "Complementary and alternative medicine in Korea: current status and future prospects," Journal of Alternative and Complementary Medicine, vol. 7, supplement 1, pp. S33S40, 2001.

[20] M. S. Hong, K. H. Chun, H. J. Song, and I. W. Park, "Attitudes towards complementary and alternative medicine in Suwon city," Korean Journal of Preventive Medicine, vol. 32, no. 2, pp. 162-169, 1999.

[21] L. Krenn and D. H. Paper, "Inhibition of angiogenesis and inflammation by an extract of red clover (Trifolium pratense L.)," Phytomedicine, vol. 16, no. 12, pp. 1083-1088, 2009.

[22] O. Wahl, M. Oswald, L. Tretzel, E. Herres, J. Arend, and T. Efferth, "Inhibition of tumor angiogenesis by antibodies, synthetic small molecules and natural products," Current Medicinal Chemistry, vol. 18, no. 21, pp. 3136-3155, 2011.

[23] C. Campa and S. P. Harding, "Anti-VEGF compounds in the treatment of neovascular age related macular degeneration," Current Drug Targets, vol. 12, no. 2, pp. 173-181, 2011.

[24] S. Wang, J. K. Park, and E. J. Duh, "Novel targets against retinal angiogenesis in diabetic retinopathy," Current Diabetes Reports, vol. 12, no. 4, pp. 355-363, 2012.

[25] T. C. Johannessen, M. Wagner, O. Straume, R. Bjerkvig, and H. P. Eikesdal, "Tumor vasculature: the Achilles' heel of cancer?" Expert Opinion Therapeutic Targets, vol. 17, no. 1, pp. 7-20, 2013.

[26] L. Anfosso, T. Efferth, A. Albini, and U. Pfeffer, "Microarray expression profiles of angiogenesis-related genes predict tumor 
cell response to artemisinins," Pharmacogenomics Journal, vol. 6, no. 4, pp. 269-278, 2006.

[27] J. Wittmann, W. Kugler, and H. Kaltner, "Cultivation of the early quail embryo: induction of embryogenesis under in vitro conditions," The Journal of Experimental Zoology, vol. 244, no. 1, pp. 325-328, 1987.

[28] P. F. D’Arcy and E. M. Howard, "A new anti-inflammatory test, utilizing the chorio-allantoic membrane of the chick embryo," British Journal of Pharmacology, vol. 29, no. 3, pp. 378-387, 1967.

[29] M. Marchesan, D. H. Paper, S. Hose, and G. Franz, "Investigations of the anti- inflammatory activity of liquid extracts of Plantago lanceolata L," Phytotherapy Research, vol. 12, no. S1, pp. 33-34, 1998.

[30] V. Kuete, B. Krusche, M. Youns et al., "Cytotoxicity of some Cameroonian spices and selected medicinal plant extracts," Journal of Ethnopharmacology, vol. 134, no. 3, pp. 803-812, 2011.

[31] U. Scherf, D. T. Ross, M. Waltham et al., "A gene expression database for the molecular pharmacology of cancer," Nature Genetics, vol. 24, no. 3, pp. 236-244, 2000.

[32] S. A. Amundson, K. T. Do, L. C. Vinikoor et al., "Integrating global gene expression and radiation survival parameters across the 60 cell lines of the National Cancer Institute Anticancer Drug Screen," Cancer Research, vol. 68, no. 2, pp. 415-424, 2008.

[33] T. Efferth, F. Herrmann, A. Tahrani, and M. Wink, "Cytotoxic activity of secondary metabolites derived from Artemisia annua L. towards cancer cells in comparison to its designated active constituent artemisinin," Phytomedicine, vol. 18, no. 11, pp. 959969, 2011.

[34] F. V. Peale Jr. and M. E. Gerritsen, "Gene profiling techniques and their application in angiogenesis and vascular development," Journal of Pathology, vol. 195, no. 1, pp. 7-19, 2001.

[35] G. M. Morris, H. Ruth, W. Lindstrom et al., "Software news and updates AutoDock4 and AutoDockTools4: automated docking with selective receptor flexibility," Journal of Computational Chemistry, vol. 30, no. 16, pp. 2785-2791, 2009.

[36] T. Efferth, S. Kahl, K. Paulus et al., "Phytochemistry and pharmacogenomics of natural products derived from traditional chinese medicine and chinese materia medica with activity against tumor cells," Molecular Cancer Therapeutics, vol. 7, no. 1, pp. 152-161, 2008.

[37] T. Efferth, F. Herrmann, A. Tahrani, and M. Wink, "Cytotoxic activity of secondary metabolites derived from Artemisia annua L. towards cancer cells in comparison to its designated active constituent artemisinin," Phytomedicine, vol. 18, no. 11, pp. 959969, 2011.

[38] T. Efferth and F. Oesch, "Oxidative stress response of tumor cells: microarray-based comparison between artemisinins and anthracyclines," Biochemical Pharmacology, vol. 68, no. 1, pp. 310, 2004.

[39] T. Efferth, "Microarray-based prediction of cytotoxicity of tumor cells to cantharidin," Oncology Reports, vol. 13, no. 3, pp. 459-463, 2005.

[40] S. Sertel, M. Tome, M. M. Briehl et al., "Factors determining sensitivity and resistance of tumor cells to arsenic trioxide," PLoS ONE, vol. 7, no. 5, Article ID e35584, 2012.

[41] H.-J. Kwak, M.-J. Park, C.-M. Park et al., "Emodin inhibits vascular endothelial growth factor-A-induced angiogenesis by blocking receptor-2 (KDR/Flk-1) phosphorylation," International Journal of Cancer, vol. 118, no. 11, pp. 2711-2720, 2006.

[42] T. Kaneshiro, T. Morioka, M. Inamine et al., "Anthraquinone derivative emodin inhibits tumor-associated angiogenesis through inhibition of extracellular signal-regulated kinase 1/2 phosphorylation," European Journal of Pharmacology, vol. 553, no. 1-3, pp. 46-53, 2006.

[43] A. A. Khan, D. S. Dace, A. G. Ryazanov, J. Kelly, and R. S. Apte, "Resveratrol regulates pathologic angiogenesis by a eukaryotic elongation factor-2 kinase-regulated pathway," American Journal of Pathology, vol. 177, no. 1, pp. 481-492, 2010.

[44] H. Wang, H. Zhou, Y. Zou et al., "Resveratrol modulates angiogenesis through the GSK3 $\beta / \beta$-catenin/TCF-dependent pathway in human endothelial cells," Biochemical Pharmacology, vol. 80, no. 9, pp. 1386-1395, 2010.

[45] S. B. Jones, S. E. DePrimo, M. L. Whitfield, and J. D. Brooks, "Resveratrol-induced gene expression profiles in human prostate cancer cells," Cancer Epidemiology Biomarkers and Prevention, vol. 14, no. 3, pp. 596-604, 2005.

[46] Z.-Y. Fu, J.-X. Han, and H.-Y. Huang, "Effects of emodin on gene expression profile in small cell lung cancer NCI-H446 cells," Chinese Medical Journal, vol. 120, no. 19, pp. 1710-1715, 2007.

[47] L. Whyte, Y.-Y. Huang, K. Torres, and R. G. Mehta, "Molecular mechanisms of resveratrol action in lung cancer cells using dual protein and microarray analyses," Cancer Research, vol. 67, no. 24, pp. 12007-12017, 2007.

[48] J. Wittmann, W. Kugler, and H. Kaltner, "Cultivation of the early quail embryo: induction of embryogenesis under in vitro conditions," Journal of Experimental Zoology, vol. 244, no. 1, pp. 325-328, 1987.

[49] R. N. Chopra, S. L. Nayar, and I. C. Chopra, Glossary of Indian Medicinal Plants (Including the Supplement), Council of Scientific and Industrial Research, New Delhi, India, 1986.

[50] S. E. Crawford, C. Mavroudis, C. L. Backer et al., "Captopril suppresses Post-transplantation angiogenic activity in rat allograft coronary vessels," Journal of Heart and Lung Transplantation, vol. 23, no. 6, pp. 666-673, 2004.

[51] C. Peifer and G. Dannhardt, "A novel quantitative chick embryo assay as an angiogenesis model using digital image analysis," Anticancer Research, vol. 24, no. 3 A, pp. 1545-1551, 2004.

[52] V. Kuete, E. J. Seo, B. Krusche et al., "Cytotoxicity and pharmacogenomics of medicinal plants from traditional Korean medicine," Evidence-Based Complementary Alternative Medicine, 2013.

[53] J. N. Weinstein, T. G. Myers, P. M. O'Connor et al., "An information-intensive approach to the molecular pharmacology of cancer," Science, vol. 275, no. 5298, pp. 343-349, 1997.

[54] S. Holbeck, J. Chang, A. M. Best, A. L. Bookout, D. J. Mangelsdorf, and E. D. Martinez, "Expression profiling of nuclear receptors in the NCI60 cancer cell panel reveals receptor-drug and receptor-gene interactions," Molecular Endocrinology, vol. 24, no. 6, pp. 1287-1296, 2010.

[55] D. G. Covell, "Integrating constitutive gene expression and chemoactivity: mining the NCI60 anticancer screen," PLoS ONE, vol. 7, no. 10, Article ID e44631, 2012.

[56] P. Wan, Q. Li, J. E. Larsen et al., "Prediction of drug efficacy for cancer treatment based on comparative analysis of chemosensitivity and gene expression data," Bioorganic \& Medicinal Chemistry, vol. 20, no. 1, pp. 167-176, 2012.

[57] T. Efferth, A. Sauerbrey, M.-E. Halatsch, D. D. Ross, and E. Gebhart, "Molecular modes of action of cephalotaxine and homoharringtonine from the coniferous tree Cephalotaxus hainanensis in human tumor cell lines," Naunyn-Schmiedeberg's Archives of Pharmacology, vol. 367, no. 1, pp. 56-67, 2003. 
[58] K. S. Radha, H. K. Madhyastha, Y. Nakajima, S. Omura, and M. Maruyama, "Emodin upregulates urokinase plasminogen activator, plasminogen activator inhibitor-1 and promotes wound healing in human fibroblasts," Vascular Pharmacology, vol. 48, no. 4-6, pp. 184-190, 2008.

[59] S. Ok, S. M. Kim, C. Kim et al., "Emodin inhibits invasion and migration of prostate and lung cancer cells by downregulating the expression of chemokine receptor CXCR4," Immunopharmacology and Immunotoxicology, vol. 34, no. 5, pp. 768-778, 2012.

[60] Y. Lu, J. Zhang, and J. Qian, "The effect of emodin on VEGF receptors in human colon cancer cells," Cancer Biotherapy and Radiopharmaceuticals, vol. 23, no. 2, pp. 222-228, 2008.

[61] J. Fang, C. Xia, Z. Cao, J. Z. Zheng, E. Reed, and B.-H. Jiang, "Apigenin inhibits VEGF and HIF-1 expression via PI3K/AKT/ p70S6K1 and HDM2/p53 pathways," The FASEB Journal, vol. 19, no. 3, pp. 342-353, 2005.

[62] L.-Z. Liu, J. Fang, Q. Zhou, X. Hu, X. Shi, and B.-H. Jiang, "Apigenin inhibits expression of vascular endothelial growth factor and angiogenesis in human lung cancer cells: implication of chemoprevention of lung cancer," Molecular Pharmacology, vol. 68, no. 3, pp. 635-643, 2005.

[63] B. R. Kim, Y. K. Jeon, and M. J. Nam, "A mechanism of apigenininduced apoptosis is potentially related to anti-angiogenesis and anti-migration in human hepatocellular carcinoma cells," Food and Chemical Toxicology, vol. 49, no. 7, pp. 1626-1632, 2011.

[64] S. Lamy, N. Akla, A. Ouanouki, S. Lord-Dufour, and R. Béliveau, "Diet-derived polyphenols inhibit angiogenesis by modulating the interleukin-6/STAT3 pathway," Experimental Cell Research, vol. 318, no. 13, pp. 1586-1596, 2012.

[65] K. Igura, T. Ohta, Y. Kuroda, and K. Kaji, "Resveratrol and quercetin inhibit angiogenesis in vitro," Cancer Letters, vol. 171, no. 1, pp. 11-16, 2001.

[66] E. Bråkenhielm, R. Cao, and Y. Cao, "Suppression of angiogenesis, tumor growth, and wound healing by resveratrol, a natural compound in red wine and grapes," The FASEB Journal, vol. 15, no. 10, pp. 1798-1800, 2001.

[67] S. Garvin, K. Öllinger, and C. Dabrosin, "Resveratrol induces apoptosis and inhibits angiogenesis in human breast cancer xenografts in vivo," Cancer Letters, vol. 231, no. 1, pp. 113-122, 2006.

[68] M.-T. Lin, M.-I. Yen, C.-Y. Lin, and M.-L. Kuo, "Inhibition of vascular endothelial growth factor-induced angiogenesis by resveratrol through interruption of src-dependent vascular endothelial cadherin tyrosine phosphorylation," Molecular Pharmacology, vol. 64, no. 5, pp. 1029-1036, 2003.

[69] S. Fukuda, S. Kaga, L. Zhan et al., "Resveratrol ameliorates myocardial damage by inducing vascular endothelial growth factor-angiogenesis and tyrosine kinase receptor Flk-1," Cell Biochemistry and Biophysics, vol. 44, no. 1, pp. 43-49, 2006.

[70] H.-B. Yu, H.-F. Zhang, X. Zhang et al., "Resveratrol inhibits VEGF expression of human hepatocellular carcinoma cells through a NF-kappa B-mediated mechanism," Hepato-Gastroenterology, vol. 57, no. 102-103, pp. 1241-1246, 2010.

[71] J. Mikuła-Pietrasik, A. Kuczmarska, M. Kucińska et al., "Resveratrol and its synthetic derivatives exert opposite effects on mesothelial cell-dependent angiogenesis via modulating secretion of VEGF and IL-8/CXCL8," Angiogenesis, vol. 15, no. 3, pp. 361-376, 2012.

[72] S. H. Yang, J. S. Kim, T. J. Oh et al., "Genome-scale analysis of resveratrol-induced gene expression profile in human ovarian cancer cells using a cDNA microarray," International Journal of Oncology, vol. 22, no. 4, pp. 741-750, 2003.

[73] Z. Huang, G. Chen, and P. Shi, "Effects of emodin on the gene expression profiling of human breast carcinoma cells," Cancer Detection and Prevention, vol. 32, no. 4, pp. 286-291, 2009.

[74] J. Cai, X.-L. Zhao, A.-W. Liu, H. Nian, and S.-H. Zhang, "Apigenin inhibits hepatoma cell growth through alteration of gene expression patterns," Phytomedicine, vol. 18, no. 5, pp. 366373, 2011.

[75] T. Efferth, "Signal transduction pathways of the epidermal growth factor receptor in colorectal cancer and their inhibition by small molecules," Current Medicinal Chemistry, vol. 19, no. 33, pp. 5735-5744, 2012.

[76] H. Wagner, "Multitarget therapy-the future of treatment for more than just functional dyspepsia," Phytomedicine, vol. 13, supplement 5, pp. 122-129, 2006.

[77] T. Efferth and E. Koch, "Complex interactions between Phytochemicals. The Multi-Target Therapeutic concept of Phytotherapy," Current Drug Targets, vol. 12, no. 1, pp. 122-132, 2011.

[78] P. Bhargava and M. O. Robinson, "Development of secondgeneration VEGFR tyrosine kinase inhibitors: current status," Current Oncology Reports, vol. 13, no. 2, pp. 103-111, 2011.

[79] T. K. Choueiri, "Axitinib, a novel anti-angiogenic drug with promising activity in various solid tumors," Current Opinion in Investigational Drugs, vol. 9, no. 6, pp. 658-671, 2008.

[80] R. J. Kelly and O. Rixe, "Axitinib-a selective inhibitor of the vascular endothelial growth factor (VEGF) receptor," Targeted Oncology, vol. 4, no. 4, pp. 297-305, 2009.

[81] D. J. Newman and G. M. Cragg, "Natural products as sources of new drugs over the 30 years from 1981 to 2010," Journal of Natural Products, vol. 75, no. 3, pp. 311-335, 2012. 


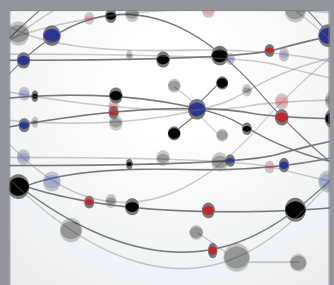

The Scientific World Journal
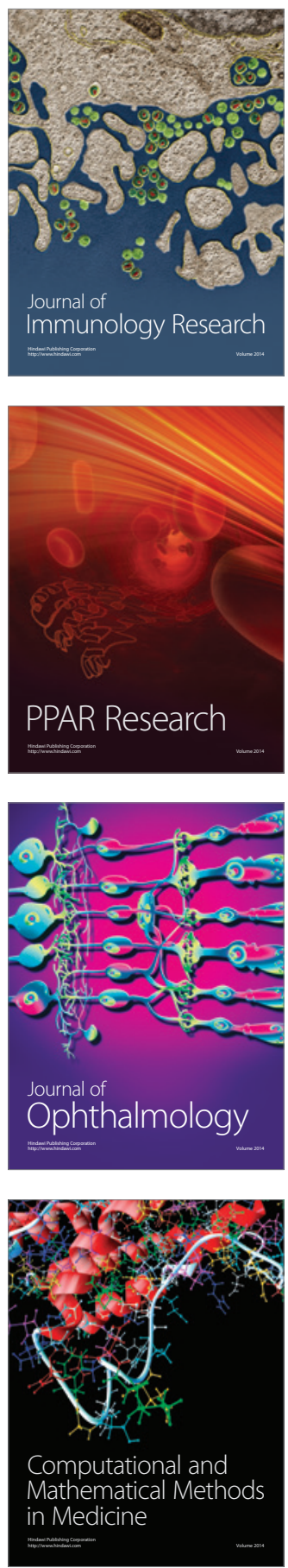

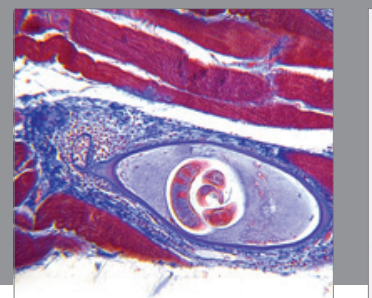

Gastroenterology

Research and Practice
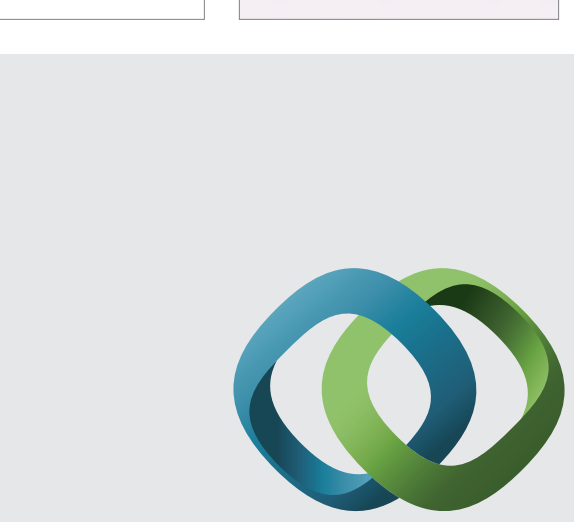

\section{Hindawi}

Submit your manuscripts at

http://www.hindawi.com
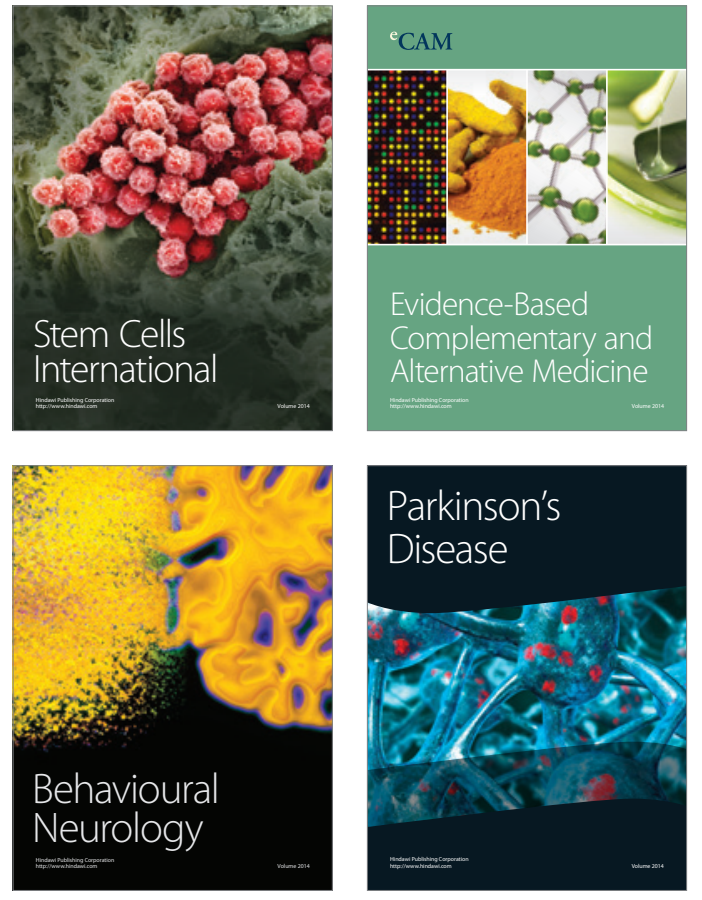
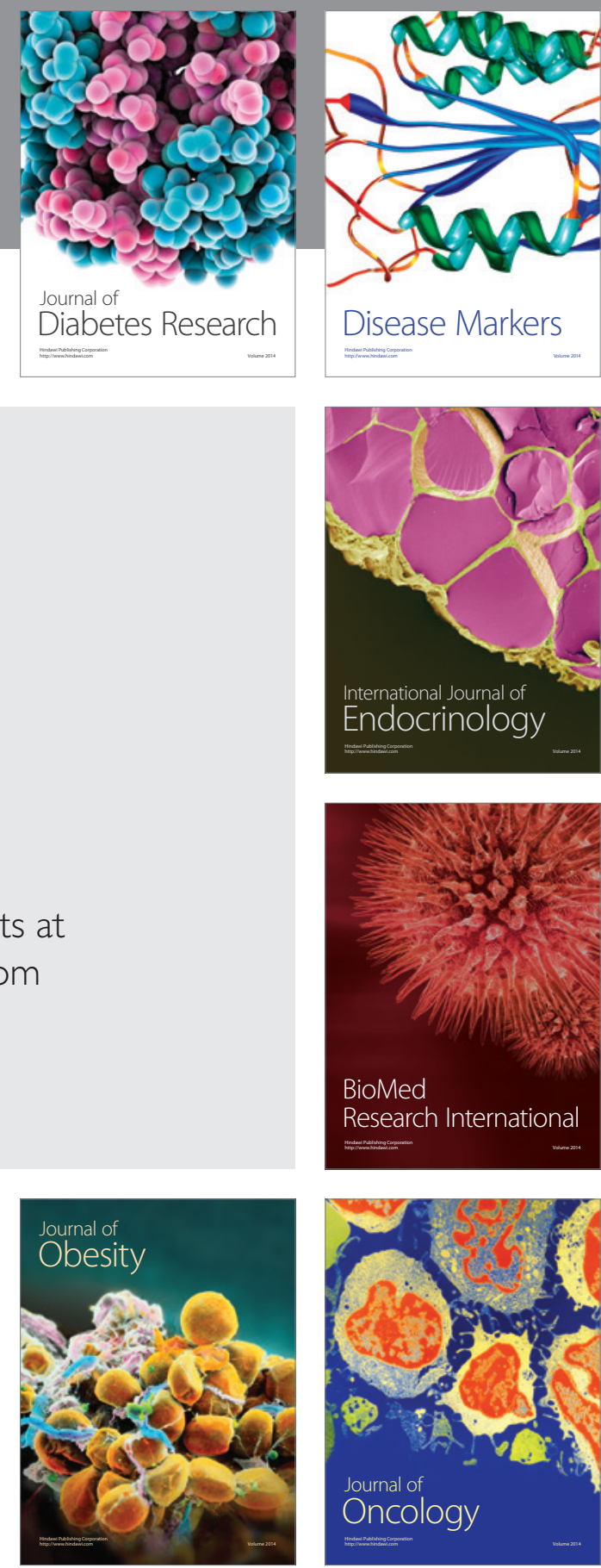

Disease Markers
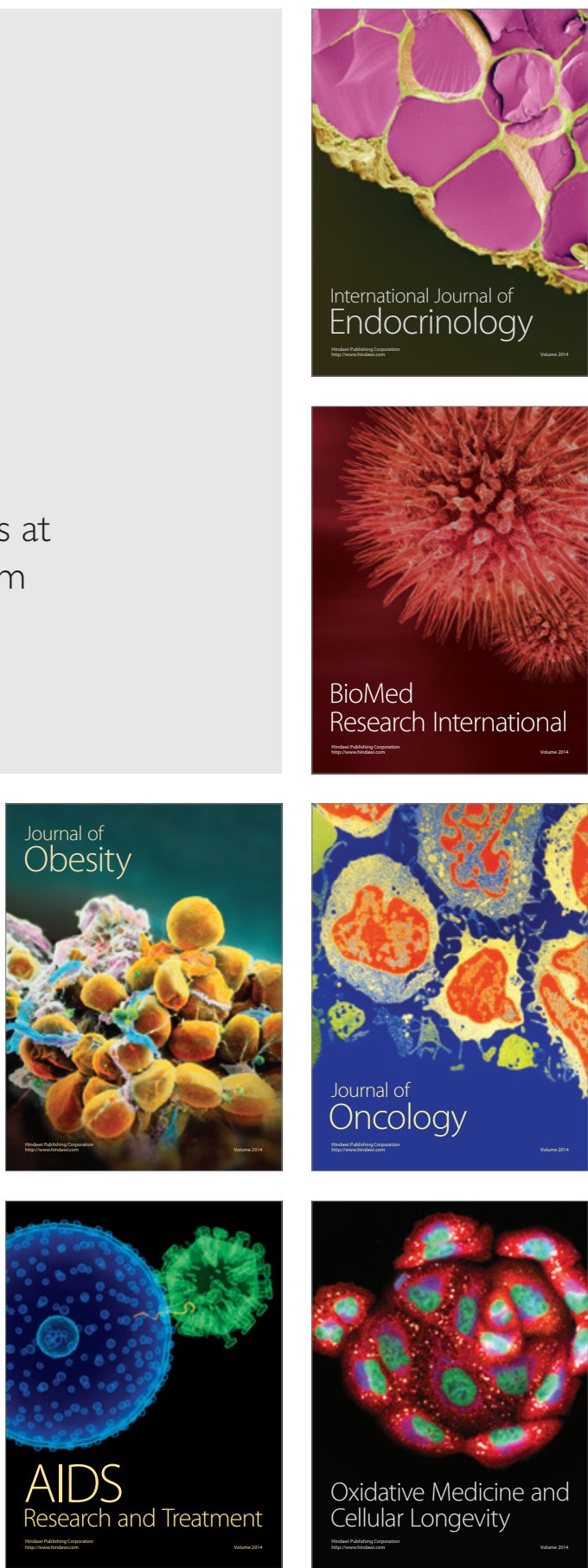